\title{
Application of procedure "pest-entomofag" in biological protection of cotton in Uzbekistan
}

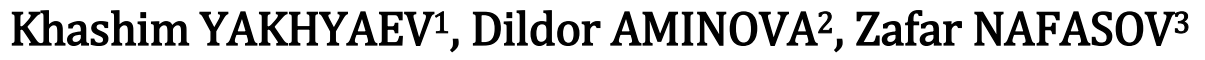 \\ Uzbek Research Institute Of Plant Protection
}

\begin{tabular}{l} 
ARTICLE INFO \\
\hline Article history: \\
Received June 2021 \\
Received in revised form \\
20 June 2021 \\
Accepted 25 July 2021 \\
Available online \\
25 August 2021
\end{tabular}

\section{Keywords:}

pest,

entomophagus,

biological protection,

biological balance.

\begin{abstract}
The problem of development of optimum plans of biological fabrics work for release of useful entomophages (trichogramma, bracon, laxe wing) against the cotton pests (Heliothis armigera) for different zones with using the methods of modeling and programming has been examined.

The period of "owner's development" (Heliothis armigera) and optimum periods of release of useful entomophages in dependence on weather conditions of the year were defined on the basis of algorithms' working out.
\end{abstract}

2181-1415/C) 2021 in Science LLC.

This is an open access article under the Attribution 4.0 International (CC BY 4.0) license (https://creativecommons.org/licenses/by/4.0/deed.ru)

\section{Ғўзани биологик химоя қилишда “зараркунанда ва энтомофаг” процедурасини кўллаш}

Калит сўзлар:

зараркунанда,

энтомофаг,

биологик химоя,

биологик мувозанат.

\section{АННОТАЦИЯ}

Мақолада республикамизнинг хар хил худудлари учун ғўза зараркунандаларига (кўсак қурти ва кузги тунлам) қарши фойдали энтомофаглар (трихограмма, бракон, олтинкўз) тарқатиш бўйича биологик фабрикаларнинг оптимал иш режаларини ишлаб чиқиш масаласини математик моделлаштириш ва дастурлаш усуллари ёрдамида хал қилиш йўллари ёритилган.

Ишлаб чиқилган алгоритимлар ва компьютер дастурлари ёрдамида зараркунандаларга қарши маълум йил обхаво шароитлари учун фойдали хашаротларни далаларга тарқатишнинг оптимал муддатлари аниқланган.

\footnotetext{
${ }^{1}$ DSc, professor, Uzbek Research Institute of Plant Protection, Tashkent, Uzbekistan.

E-mail: axashim@mail.ru.

${ }^{2} \mathrm{PhD}$, Uzbek Research Institute of Plant Protection, Tashkent, Uzbekistan.

${ }^{3} \mathrm{PhD}$, senior researcher, Uzbek Research Institute of Plant Protection, Tashkent, Uzbekistan.

E-mail: nafasov85@gmail.ru.
} 


\section{Применение процедуры «вредитель-энтомофаг» биологической защите хлопчатника}

Ключевые слова:
вредитель,
энтомофаг,
биологическая защита,
биологическое
равновесие.

\begin{abstract}
АННОТАЦИЯ
В данной статье рассмотрены вопросы разработки оптимальных планов работ биологических фабрик по выпуску полезной энтомофауны (трихограмма, бракон, златоглазка) против вредителей хлопчатника (хлопковая и озимая совки) для различных зон республики с применением методов математического моделирования и программирования.

С помощью разработанных алгоритмов и компьютерных программ борьбы с вредителями определены оптимальные сроки распространения полезных насекомых на полях для определенных погодных условий года.
\end{abstract}

Практиковавшаяся в прошедшие десятилетия система борьбы с вредными организмами преимущественно за счет массированного использования химических средств (особенно при недостаточно обоснованном их применении), в экологическом и экономическом отношениях приводила к возникновению серьезных проблем связанных с отрицательным воздействием на окружающую среду и появлением устойчивости вредных организмов к средствам защиты растений. Отчасти это даже способствовало прямому или косвенному усилению вредоносности определенных видов вредителей и болезней и все большой зависимости урожая от эффективности мероприятий по борьбе с ними.

Так для борьбы с сосущими вредителями главную позицию занимает применение естественных энтомофагов (трихограмма, бракон, златоглазка и др.). Большую роль при этом играет увеличение численности (плотности) этих полезных насекомых путем искусственного разведения, сезонной колонизации их против вредителей. С этой целью в республике строились и успешно функционируют биологические лаборатории и фабрики по выращиванию и размножению паразитов.

Для наиболее эффективной работы этих биологических фабрик необходимо разработать оптимальные планы борьбы с сельскохозяйственными вредителями, которые будут определять план выпуска паразитов (энтомофагов) в зависимости от имеющегося прогноза численности (плотности) хозяина (вредителя). А разработка оптимальных планов борьбы, в свою очередь, являясь довольно сложной задачей, требует предварительного математического моделирования динамики популяции сельскохозяйственных вредителей.

Как было отмечено в [1], среди биологической борьбы наиболее эффективным является метод массового выпуска «энтомофагов», которые выращиваются в лабораторных условиях. Отсюда вытекает задача разработки оптимальных планов работ этих биологических фабрик (сроки и нормы выпуска «энтомофагов») в зависимости от складывающихся условий года. Например, против 
хлопковой совки (Helicoverpa Armigera) успешно используется паразит из рода Trichogramma, который паразитирует яйца этого вредителя. Хотя авторы работы [2] считают, что «паразит» этого рода имеет очень низкие поисковые способности, которые мешают ей стать агентом биологической борьбы. Но по данным Ю.Н. Фадеева (примечание к работе [2]) эти препятствия можно устранить, применяя метод «наводнения», при котором численность паразита поддерживается на достаточно высоком уровне путем периодических массовых выпусков «паразита» в агробиоценозе. В этом случае приемлемость метода определяется чисто экономическими соображениями. По своей природе трихограммы заражают яйца вредителя. Следовательно, правильное прогнозирование сроков массовых яйцекладок вредителя повышает эффективность применения этого вида паразита по борьбе с вредителями. При реализации этой задачи в работе $[3,4]$ были сделаны следующие допущения:

1) В силу малого периода жизни трихограмм, равным 3-5 дням, слагаемые $\mathrm{f}_{1}\left(\mathrm{R}_{1}, \mathrm{~V}_{1}, \mathrm{t}_{1}\right)-\mathrm{g}_{1}\left(\mathrm{R}_{1}{ }^{*}, \mathrm{~V}_{1}{ }^{*}, \mathrm{t}_{1}{ }^{*}\right)$ и $\mathrm{f}_{2}\left(\mathrm{R}_{2}, \mathrm{~V}_{2}, \mathrm{t}_{2}\right)-\mathrm{g}_{2}\left(\mathrm{R}_{2}{ }^{*}, \mathrm{~V}_{2}{ }^{*}, \mathrm{t}_{2}{ }^{*}\right)$

как коэффициенты прироста приравняли к нулю;

2) вместо коэффициента частоты встречаемости «паразита» и «хозяина» использован коэффициент интенсивности поражения «хозяев» «паразитами». Этот показатель был определен экспериментально, из соотношения доли «хозяев»к зараженным особям.

Тогда выражение (3.32) из [3, 4] принимал вид

$$
\begin{gathered}
\mathrm{N}_{1} \mathrm{k}(\mathrm{t}+1)=\mathrm{N}_{1} \mathrm{k}(\mathrm{t})-\mathrm{mN}_{1} \mathrm{k}(\mathrm{t}) \mathrm{N}_{2^{\mathrm{k}}}(\mathrm{t}) \\
\mathrm{N}_{2} \mathrm{k}(\mathrm{t}+1)=\mathrm{N}_{2} \mathrm{k}(\mathrm{t})-\mathrm{mN}_{1} \mathrm{k}(\mathrm{t}) \mathrm{N}_{2} \mathrm{k}(\mathrm{t})(3.1)
\end{gathered}
$$

Таким образом, задача сводилась к нахождению таких оптимальных значений $\mathrm{N}_{2}{ }^{\mathrm{k}}(\mathrm{t})$ из (3.1), удовлетворяющим системе ограничений (3.33) и обеспечивающий минимум функционала (3.34) из [3].

Установлено, что коэффициент интенсивности (m) поражения хозяев паразитами, определяемый в лабораторных условиях, дает большие погрешности в полевых условиях. Так как, в самом деле, $\mathrm{m}$ прямо зависит от численности вредителя. Если S - число зараженных яиц жертв, то интенсивность поражения хозяев паразитами будет равна

$$
\mathrm{m}=\mathrm{S}: \mathrm{N}_{1}
$$

С учетом этого и согласно выражению (3.33) из [3] для т можно записать

$$
\mathrm{m}=\left(\mathrm{e}^{\mathrm{aN}} 2-1\right): \mathrm{e}^{\mathrm{aN}} 2(3.2)
$$

где а - поисковая площадь (средняя площадь которую обыскивает паразит в течении своей жизни). Поисковая площадь зависит от поисковой способности паразита и определяется по полевым данным или в лабораторных условиях. Тогда выражение (3.1) с учетом (3.2) примет вид

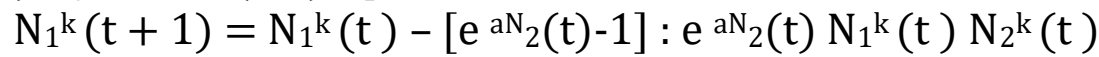

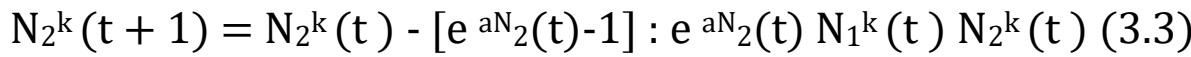

На основе (3.3) и с применением метода случайного поиска определены оптимальные нормы выпуска паразита (трихограммы) при заданных прогнозных значениях хозяина (хлопковой совки) при $\mathrm{a}=0,01$. Результаты расчета приведены в таблице 1. Из данных табл. 1. видно, что при наличии хозяина на поле необходимо 
определенное количество трихограммы. Например, если численность хлопковой совки на 100 растений равна 7, то необходимо выпустить трихограмму в норме 1,58 г/га, а если этот показатель равна 10, то 1,46 г/га и т.д. В сельскохозяйственном производстве республики норма выпуска трихограммы равна 3 г/га. Численность хозяина при этом не учитывается.

Это позволяет заключить, что на основании таких расчетов возможно планирование работ биологических фабрик по наработке биоматериала в зависимости от численности хозяина в конкретном хозяйственном году для конкретного региона хлопкосеяния.

Таким образом, для определения оптимальных сроков появления основных вредителей хлопчатника хлопковой и озимой совок в зависимости от среднемноголетних и фактических данных для разных зон хлопкосеяния республики разработаны математические модели и их алгоритмы. На основе этих алгоритмов составлена программа определения сроков появления хлопковой и озимой совок и внедрены в практической деятельности центров защиты растений Кашкадарьинской, Хорезмской и Наманганской областей. Результаты исследований приводятся в таблице 2. По данным таблицы 2 видно, что кроме сроков развития хлопковой совки выявлены оптимальные сроки выпуска таких полезных энтомофагов, как трихограмма, златоглазка и бракон.

Таблица 1.

Нормы выпуска трихограммы при заданных значениях хлопковой совки

\begin{tabular}{|c|c|c|c|}
\hline \multirow{2}{*}{$\begin{array}{c}\text { No № } \\
\text { пп }\end{array}$} & \multirow{2}{*}{$\begin{array}{c}\text { Численность хозяина на } \mathbf{1 0 0} \\
\text { растений, в шт. }\end{array}$} & \multicolumn{2}{|c|}{$\begin{array}{c}\text { Оптимальные значения паразита выпускаемой } \\
\text { биофабрикой }\end{array}$} \\
\cline { 3 - 4 } & 7.0 & В штуках & В граммах \\
\hline $\mathbf{1 .}$ & 7.5 & 158221.0 & 1,58 \\
\hline $\mathbf{2 .}$ & 8.0 & 158010.0 & 1,58 \\
\hline $\mathbf{3 .}$ & 8.5 & 152930.0 & 1,53 \\
\hline $\mathbf{4 .}$ & 9.0 & 152448.0 & 1,52 \\
\hline $\mathbf{5 .}$ & 9.5 & 150025.0 & 1,50 \\
\hline $\mathbf{6 .}$ & 10.0 & 147842.0 & 1,48 \\
\hline $\mathbf{7 .}$ & 10.5 & 146200.0 & 1,46 \\
\hline $\mathbf{8 .}$ & 11.0 & 145830.0 & 1,46 \\
\hline $\mathbf{9 .}$ & 11.5 & 143990.0 & 1,44 \\
\hline $\mathbf{1 0 .}$ & 12.0 & 142650.0 & 1,42 \\
\hline $\mathbf{1 1 .}$ & & 141100.0 & 1,41 \\
\hline
\end{tabular}

Кроме вышеизложенного необходимо отметить то, что при биологической защите растений от вредителей необходимо учитывать создания биологического равновесия между насекомыми (вредителями) и их естественными врагами (энтомофагами). В природных условиях равновесие между ними устанавливается автоматически. Биологическое равновесие является подвижным, и оно сдвигается в ту или другую сторону. 
Таблица 2.

Развитие хлопковой совки и оптимальные сроки проведения биологической защиты

(Первая хлопковая генерация, 2020 г.)

\begin{tabular}{|c|c|c|c|c|c|c|c|}
\hline \multirow[b]{2}{*}{$\begin{array}{c}\text { Вилояты, } \\
\text { туманы }\end{array}$} & \multicolumn{4}{|c|}{ Сроки развития (день, месяц) } & \multicolumn{3}{|c|}{ Сроки выпуска энтомофагов (день, месяц) } \\
\hline & $\begin{array}{c}\text { Яйце- } \\
\text { кладка }\end{array}$ & $\begin{array}{c}\text { Гусеницы } \\
\text { 2-го } \\
\text { возраста } \\
\end{array}$ & $\begin{array}{c}\text { Гусеницы } \\
\text { 4-го возраста }\end{array}$ & $\begin{array}{c}\text { Гусеницы 6- } \\
\text { го возраста }\end{array}$ & Трихограмма & Златоглазка & Бракон \\
\hline \multirow{3}{*}{$\begin{array}{c}\text { Наманганский } \\
\text { Папский } \\
\text { Учкурганский }\end{array}$} & & & & & & & \\
\hline & 7 июня & 13 июня & 19 июня & 24 июня & 6-8 июня & 7,13 июня & 19,24 июня \\
\hline & 9 июня & 15 июня & 20 июня & 25 июня & 8-10 июня & 9, 15 июня & 20,25 июня \\
\hline \multirow{3}{*}{$\begin{array}{c}\text { Кашкадарьинский } \\
\text { Касанский, } \\
\text { Нишанский } \\
\end{array}$} & & & & & & & \\
\hline & 3 июня & 9 июня & 15 июня & 20 июня & 2-4 июня & 3, 9 июня & 15,20 июня \\
\hline & 2 июня & 8 июня & 14 июня & 19 июня & $1-3$ июня & 2,8 июня & 14,19 июня \\
\hline \multirow{3}{*}{$\begin{array}{c}\text { Хорезмский } \\
\text { Ургенчский, } \\
\text { Шаватский } \\
\end{array}$} & & & & & & & \\
\hline & 3 июня & 9 июня & 14 июня & 19 июня & $2-4$ июня & 3,9 июня & 14,19 июня \\
\hline & 2 июня & 8 июня & 13 июня & 18 июня & 1-3 июня & 2,8 июня & 13,18 июня \\
\hline
\end{tabular}




\section{БИБЛИОГРАФИЧЕСКИЕ ССЫЛКИ:}

1. Таджибаева К., Яхяев Х.К. Математические модели определения оптимальных планов работ биологических фабрик // Вопросы РАСУ. -Ташкент.: РИСО АН УЗССР. 1985. - вып. 38. - С. 80-87.

2. Фадеев Ю.Н. Интегрированная борьба и управление популяции вредных организмов // Защита растений. 1979. №!. - С. 18-19.

3. Яхяев Х.К. Разработка научных основ автоматизации прогнозирования и управления вредными объектами сельскохозяйственных культур. - Дисс. ... доктора с/х наук. - Ташкент. 1994. - С. 286.

4. Яхяев Х.К., Розет И.Г. Эталонные режимы и оптимизационное отношение экологического взаимодействия трихограмма-хлопковая совка // Вопросы кибернетики. - Ташкент: РИСО АН УзССР 1984. - вып. 128. - С. 29-36.

5. Яхяев Х.Қ., Нафасов 3.Н. Автоматизированная система мониторинга развития и распространения вредных организмов лесохозяйственных культур. Общество и инновации. - Ташкент, 2020. №1. ISSN 2181-1415. - С. 61-67. 